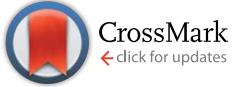

Cite this: Chem. Sci., 2015, 6, 1341

Received 31st October 2014

Accepted 27th November 2014

DOI: $10.1039 / c 4 s c 03342 f$

www.rsc.org/chemicalscience

\section{Utilizing the electron transfer mechanism of chlorophyll a under light for controlled radical polymerization $\uparrow$}

\begin{abstract}
Sivaprakash Shanmugam, Jiangtao $\mathrm{Xu}^{*}$ and Cyrille Boyer*
Efficient photoredox catalysts containing transition metals, such as iridium and ruthenium, to initiate organic reactions and polymerization under visible light have recently emerged. However, these catalysts are composed of rare metals, which limit their applications. In this study, we report an efficient photoinduced living radical polymerization process that involves the use of chlorophyll as the photoredox biocatalyst. We demonstrate that chlorophyll a (the most abundant chlorophyll in plants) can activate a photoinduced electron transfer (PET) process that initiates a reversible addition-fragmentation chain transfer (RAFT) polymerization under blue and red LED light ( $\lambda_{\max }=461$ and $635 \mathrm{~nm}$, respectively). This process controls a wide range of functional and non-functional monomers, and offers excellent control over molecular weights and polydispersities. The end group fidelity was demonstrated by NMR, UV-vis spectroscopy, and successful chain extensions for the preparation of diblock copolymers.
\end{abstract}

\section{Introduction}

The inhabitation of Earth by cyanobacteria approximately 3.4 billion years ago led to the development of an efficient chemical process called photosynthesis. Through photosynthesis, plants, algae and some species of bacteria are able to harvest and convert solar energy to chemical energy to synthesize polysaccharide and natural polymers. ${ }^{1}$ Currently, various research groups have undertaken great efforts to mimic and engineer this sophisticated process through artificial means, which could improve our understanding of the bioenergetics process; lead to the development of more eco-friendly systems, including renewable energy production (solar fuels) and more efficient chemical reactions; and give rise to potential applications in optoelectronics, photonics and sensor design. ${ }^{2}$ In photosynthesis, sunlight is absorbed and converted to electronic excitation energy, which initiates a sequence of photoinduced electron transfer (PET) events and the synthesis of carbohydrates via the Calvin-Benson cycle. ${ }^{3}$ Over the past five years, organic chemists, inspired by this process, have developed a technique based on visible light photoredox catalysis to perform synthetic organic transformations. ${ }^{4-9}$ This approach relies on the ability of metal complexes and organic dyes to engage in single-electron transfer processes with organic substrates upon

Centre for Advanced Macromolecular Design and Australian Centre for NanoMedicine, School of Chemical Engineering, The University of New South Wales, Sydney, NSW 2052, Australia. E-mail: cboyer@unsw.edu.au; j.xu@unsw.edu.au; Fax: +6129385 4749

$\uparrow$ Electronic supplementary information (ESI) available: Experimental details, Table S1 and Fig. S1-13. See DOI: 10.1039/c4sc03342f photoexcitation with visible light. Additionally, these photosensitizers could be utilized to initiate photopolymerization reactions via free radical or cationic mechanisms..$^{10-13}$ Recently, Hawker's $\mathrm{s}^{14-19}$ and our research group ${ }^{20,21}$ developed new polymerization techniques using photoredox catalysts, such as ruthenium- and iridium-based complexes, to exploit the electrons generated during the PET process and activate/mediate controlled/“living” radical polymerization under visible light. In our work, ${ }^{20,21}$ we established a photoinduced electron transferreversible addition-fragmentation chain transfer (PET-RAFT) technique that utilizes a PET mechanism to activate thiocarbonylthio compounds to generate radicals and thereby initiate controlled free radical polymerization. Subject to the selection of photocatalysts, i.e., iridium- or ruthenium-based catalysts, a great diversity of monomers were successfully polymerized with excellent control over molecular weights, polydispersities and specific sequences. Although these catalysts are extremely efficient in conducting PET processes for organic transformation or polymerization, they present several deficiencies. First, the catalysts are composed of rare and expensive metals, such as ruthenium and iridium, which limit their potential applications in industry because the metals are found in trace quantities in the Earth's crust $(<1 \mathrm{ppm}){ }^{22}$ Second, ruthenium and iridium complexes are toxic and require several additional purification steps to eliminate any potentially adverse effects they may have in the application of final products. ${ }^{23}$ Therefore, the development of renewable catalysts from bio-resources, capable of conducting the PET process, is highly desirable.

The most abundant natural visible light photocatalyst for PET processes on Earth is chlorophyll, which is the principal 
photoacceptor in the chloroplasts of most green plants. During photosynthesis, the absorption of a photon excites the chlorophyll from its ground state to its excited state and initiates an electron transfer reaction. This high-energy electron can have several fates. The electron could return to the ground state, with the absorbed energy converted to heat or fluorescence. However, if a suitable electron acceptor with high electron affinity is close to the chlorophyll molecule, the excited electron can be transferred from the initial chlorophyll molecule to the acceptor and generate a positive charge on the chlorophyll molecule (due to the loss of an electron) and a negative charge on the acceptor. ${ }^{24}$ This process is also referred to as photoinduced charge separation. In plants, the electron extracted from chlorophyll is used to reduce species such as water and $\mathrm{CO}_{2}$. Despite ongoing research on artificial photosynthesis for solar energy conversion, this is the first example of chlorophyll being used as an efficient photoredox catalyst for the production of high-performance polymeric materials via living polymerization. In this study, we discovered that chlorophyll a (Chl a, the most widely distributed form of chlorophyll) could mediate PET-RAFT process and lead to the production of well-defined polymers with controlled molecular weights, polydispersities and end group functionalities.

Because spinach is an affordable and renewable feedstock, it can be used as the raw material for the extraction, isolation and characterization of $\mathrm{Chl} \mathrm{a.}{ }^{25} \mathrm{Chl}$ a was extracted from spinach leaves and purified by column chromatography as previously reported. ${ }^{25,26}$ Water miscible solvents such as pyridine, methanol, ethanol, acetone, $N, N$-dimethylformamide (DMF) and dimethylsulfoxide (DMSO) are most suitable for extraction of chlorophyll. Extraction in the absence of a suitable solvent may lead to oxidation or hydrolysis of chlorophyll molecules. ${ }^{27,28}$ The structure of Chl a and its purity were confirmed by proton nuclear magnetic resonance $\left({ }^{1} \mathrm{H} \mathrm{NMR}\right)$ and UV-vis spectroscopy (ESI, Fig. S2 $\dagger$ ) and compared to the data reported in the literature. ${ }^{27,29,30}$ The concentration of $\mathrm{Chl}$ a was determined by spectral measurements based on the equation developed by Wellburn. ${ }^{27}$ In our experiments, $24 \mathrm{mg}$ of Chl a was extracted from $100 \mathrm{~g}$ of spinach leaves. Inspired by our early work on PETRAFT polymerization with iridium and ruthenium complexes, ${ }^{20,21,31}$ we decided to test $\mathrm{Chl}$ a as a potential photoredox catalyst to conduct a photocontrolled radical polymerization in the presence of thiocarbonylthio compounds (RAFT agents) (Scheme 1). Chl a is reported to have a half-wave reduction potential of $-1.1 \mathrm{~V}$ in DMSO versus the saturated calomel electrode (SCE) in the excited state. ${ }^{28,32,33}$ Consequently, Chl a is a strong reducing agent capable of transferring an electron to an oxidant of lower reduction potential to yield a $\pi$ cation radical. As the magnesium center in Chl a (Scheme $1 \mathrm{~B}$ ) is a redox-neutral metal, the electron does not originate from the metal center of the Chl a molecule but from the aromatic $\pi$ electron system of the porphyrin. This mechanism is in direct contrast with the electron generation mechanism of transition metal photocatalysts (such as ruthenium and iridium) because these photocatalysts rely on metal to ligand charge transfer (MLCT) ${ }^{20,21}$ The resultant positive charge of the cationic Chl a and the spin of the unpaired electron are delocalized extensively over the $\pi$-electron system. ${ }^{32}$

The theory of reversible one electron oxidation of $\mathrm{Chl}$ a to generate $\pi$-cation radical has been reported by ferric chloride oxidation, electrolytic oxidation and charge transfer with zinc tetraphenylporphyrin perchlorate $\left(\mathrm{ZnPh}_{4} \mathrm{P}^{+\cdot}\right) \cdot{ }^{34,35}$ In electrolytic oxidation, Chl a underwent one electron oxidation to yield a yellow solution which displayed no strong visible fluorescence. $^{34,36}$ Electron paramagnetic resonance (EPR) and absorption studies on this oxidized product proved the presence of $\pi$ cation radical of $\mathrm{Chl}$ a that could be reduced to regenerate $90 \%$ of $\mathrm{Chl}$ a upon electroreduction. In addition, $\pi$-cation radical $\mathrm{Chl}$ a was sufficiently stable to permit its electromigration as a cation to establish its ionic nature through electrophoresis.

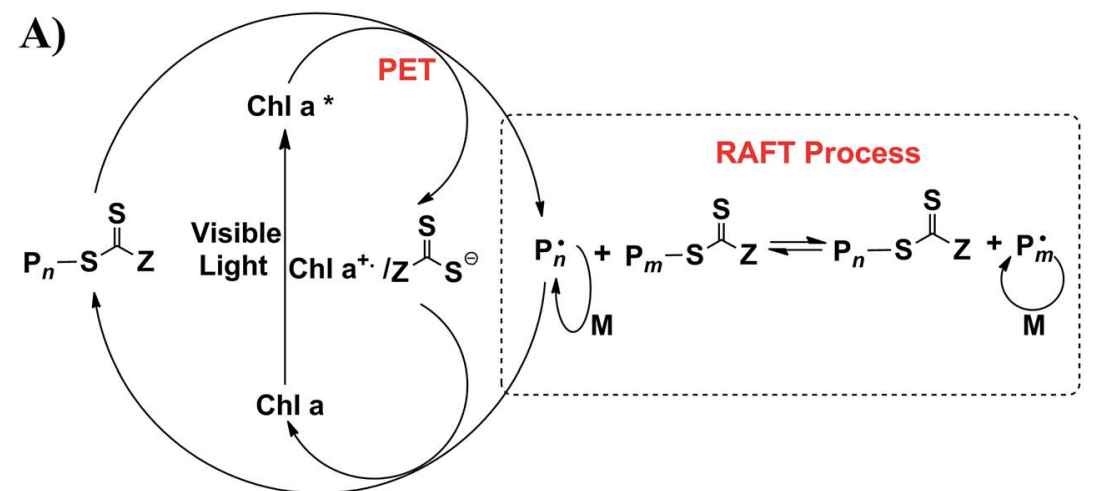

B)
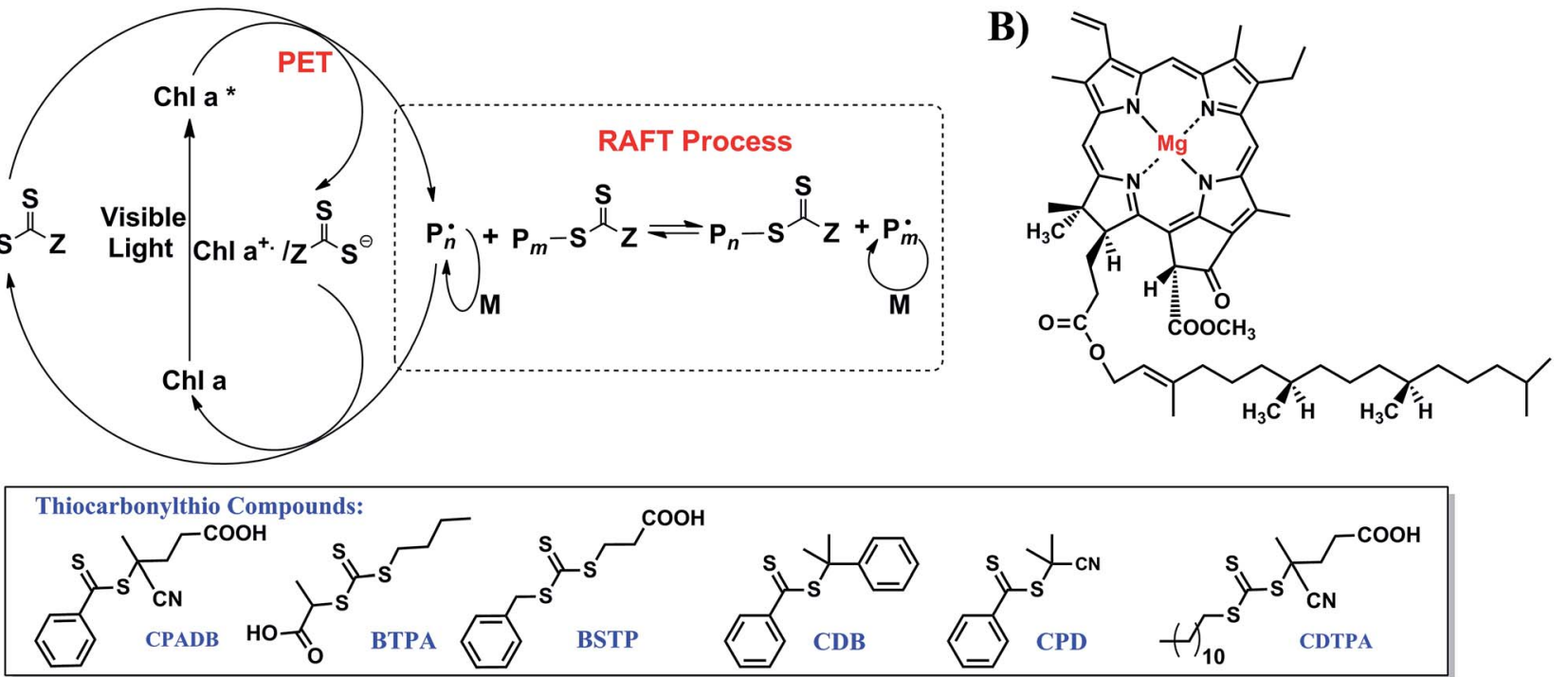

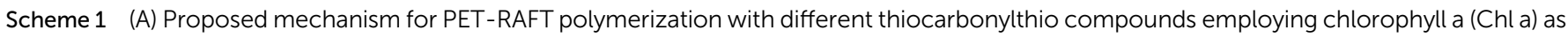
biocatalyst and (B) the chemical structure of Chl a. 
There is also a possibility for $\pi$-cation radical $\mathrm{Chl}$ a to form dimers $\left(2 \mathrm{Chl}^{+\cdot}=\left(\mathrm{Chl}^{+\cdot}\right)_{2}\right)$. However, the formation of dimer is an unlikely pathway as EPR signal of the postulated dimer would require the dimer to be weakly coupled and previous studies on magnesium octaethylporphyrin cation radical displayed no EPR signal. In addition, El Khouly et al. have shown that deactivation of $\pi$-cation radical $\mathrm{Chl}$ a upon electron transfer from ${ }^{3} \mathrm{Chl} \mathrm{a*} /{ }^{3} \mathrm{Chl} \mathrm{b*}$ to $\mathrm{C}_{60} / \mathrm{C}_{70}$ takes place through diffusion controlled back electron transfer. ${ }^{24}$ Therefore, the $\pi$ cation radical species generated through oxidation is capable of extracting an electron from a reducing agent to form the ground state. The reduction of a RAFT agent leads to the generation of a radical $\left(\mathrm{P}^{*}\right)$ capable of initiating RAFT polymerization as well as serving as a chain transfer agent. Upon addition of propagating radical $\left(\mathrm{P}^{*}\right)$ to the $\pi$-cation radical $\mathrm{Chl}$ a-thiocarbonylthio complex (Scheme 1A), deactivation of polymerization takes place to yield dormant propagating chain and uncharged $\mathrm{Chl} \mathrm{a,}$ thereby restarting the catalytic cycle. In another possible but unlikely pathway of deactivation, $\pi$-cation radical $\mathrm{Chl}$ a-thiocarbonylthio complex directly abstracts an electron from the propagating radical $\left(\mathrm{P}^{*}\right)$ to regenerate dormant propagating chain and $\mathrm{Chl}$ a. However, the generation of cationic propagating radical will be energetically unfavorable. In addition, there is also a possibility of regenerating $\mathrm{Chl}$ a from $\pi$-cation radical Chl a-thiocarbonylthio complex through disproportionation of $\pi$-cation radical $\mathrm{Chl}$ a to $\mathrm{Chl}$ a and a di-cation radical $\mathrm{Chl} \mathrm{a}\left(\mathrm{Chl} \mathrm{a}^{2+}\right)$ which can be reduced by nucleophiles and water to form allomers of $\mathrm{Chl} \mathrm{a.}{ }^{34}$

To confirm that the polymerizations were activated by $\mathrm{Chl}$ a and RAFT agent, a range of control experiments was carried out in detail under blue and red light emitting diode (LED) lights. Firstly, the methyl methacrylate (MMA) and methyl acrylate (MA) polymerizations, containing RAFT agents, Chl a and monomers, were performed in the absence of light. In these conditions, no monomer conversion was detected by NMR and gel permeation chromatography (GPC) analysis (data not shown), which demonstrated that the light is required to activate the polymerization. Secondly, the polymerizations were performed in the absence of Chl a or RAFT agents. Upon 10 hours of red light irradiation and $4 \mathrm{ppm}$ of $\mathrm{Chl}$ a with respect to monomer concentration in the absence of RAFT agent (2- $(n-$ butyltrithiocarbonate)-propionic acid, BTPA), MA showed a negligible conversion to polymer (Table 1, \# 2); on the other hand, MMA remained inert even after 13 hours of irradiation (Table 1, \# 10). An interesting fact to note was that similar results were achieved for control experiment carried out with MMA in the presence of blue light as no polymerization was observed (ESI, Table S1,†\#2). These results demonstrated that

Table 1 PET-RAFT Polymerization of a variety of monomers using Chl a as biocatalyst and $4.8 \mathrm{~W}$ red LED lamp as a light source $\left(\lambda_{\max }=635 \mathrm{~nm}\right)$

\begin{tabular}{|c|c|c|c|c|c|c|c|c|c|}
\hline \# & Exp. Cond. ${ }^{a}[M]:[$ RAFT agent $]:[\mathrm{Chl}$ a $]$ & Monomer & $\begin{array}{l}\text { RAFT } \\
\text { agent }\end{array}$ & $\begin{array}{l}{[\mathrm{Chl} \mathrm{a}] /[M]} \\
(\mathrm{ppm})\end{array}$ & Time (h) & $\alpha^{b}(\%)$ & $M_{\mathrm{n}, \mathrm{th} .}{ }^{c}\left(\mathrm{~g} \mathrm{~mol}^{-1}\right)$ & $M_{\mathrm{n}, \mathrm{GPC}}{ }^{d}\left(\mathrm{~g} \mathrm{~mol}^{-1}\right)$ & $M_{\mathrm{w}} / M_{\mathrm{n}}$ \\
\hline 1 & $200: 1: 8 \times 10^{-4}$ & MA & BTPA & 4 & 5 & 76 & 13300 & 10800 & 1.06 \\
\hline 2 & $200: 0: 8 \times 10^{-4}$ & MA & - & 4 & 10 & 6 & - & - & - \\
\hline 3 & $200: 1: 8 \times 10^{-4}$ & MMA & CPADB & 4 & 4 & 24 & 5100 & 6570 & 1.10 \\
\hline 4 & $200: 1: 8 \times 10^{-4}$ & MMA & CPADB & 4 & 20 & 50 & 10300 & 14650 & 1.14 \\
\hline 5 & $200: 1: 8 \times 10^{-4}$ & MMA & CPADB & 4 & 36 & 94 & 19100 & 20300 & 1.13 \\
\hline 6 & $200: 1: 2 \times 10^{-3}$ & MMA & CPADB & 10 & 25 & 94 & 19100 & 20420 & 1.16 \\
\hline 7 & $200: 1: 5 \times 10^{-3}$ & MMA & CPADB & 25 & 25 & 71 & 14500 & 16700 & 1.13 \\
\hline 8 & $200: 1: 5 \times 10^{-3}$ & MMA & CPADB & 25 & 15 & 50 & 10300 & 12360 & 1.15 \\
\hline 9 & $200: 1: 5 \times 10^{-3}$ & MMA & CPADB & 25 & 10 & 29 & 6100 & 8400 & 1.12 \\
\hline 10 & $200: 0: 8 \times 10^{-4}$ & MMA & - & 4 & 20 & 0 & - & - & - \\
\hline 11 & $200: 1: 8 \times 10^{-4}$ & NIPAAm & BTPA & 4 & 4 & 47 & 10900 & 13970 & 1.08 \\
\hline 12 & $200: 1: 8 \times 10^{-4}$ & HPMA & CPADB & 4 & 12 & 53 & 15600 & $9800(15900)^{i}$ & 1.05 \\
\hline 13 & $200: 1: 8 \times 10^{-4}$ & HEMA & CPADB & 4 & 6 & 77 & 20330 & 22700 & 1.09 \\
\hline 14 & $200: 1: 8 \times 10^{-4}$ & PFPA & BTPA & 4 & 6 & 55 & 26180 & 22300 & 1.08 \\
\hline 15 & $200: 1: 8 \times 10^{-4}$ & GMA & CPADB & 4 & 12 & 53 & 15330 & 16300 & 1.12 \\
\hline 16 & $200: 1: 8 \times 10^{-4}$ & DMAEMA & CPADB & 4 & 14 & 20 & 6300 & 9600 & 1.18 \\
\hline 17 & $200: 1: 0$ & DMAEMA & CPADB & 0 & 10 & 0 & - & - & - \\
\hline 18 & $200: 1: 8 \times 10^{-4}$ & MA & BSTP & 4 & 3 & 41 & 7340 & 7920 & 1.20 \\
\hline 19 & $370: 1: 8 \times 10^{-4}$ & MMA & CDB & 4 & 12 & 33 & 12500 & 15550 & 1.27 \\
\hline 20 & $200: 1: 8 \times 10^{-4}$ & MMA & CPD & 4 & 12 & 60 & 12240 & 13700 & 1.17 \\
\hline 21 & $200: 1: 8 \times 10^{-4}$ & MMA & CDTPA & 4 & 14 & 79 & 16200 & 12800 & 1.17 \\
\hline $22^{f}$ & $200: 1: 8 \times 10^{-4}$ & MA & BTPA & 4 & 8 & 53 & 9400 & 11500 & 1.07 \\
\hline $23^{g}$ & $200: 1: 8 \times 10^{-4}$ & MA & BTPA & 4 & 20 & 44 & 7800 & 8700 & 1.06 \\
\hline $24^{j}$ & $200: 1: 8 \times 10^{-4}$ & MMA-stat-MAA $^{e}$ & CPADB & 4 & 9 & $\mathrm{ND}^{h}$ & $\mathrm{ND}^{h}$ & 25000 & 1.19 \\
\hline
\end{tabular}

${ }^{a}$ The polymerizations were performed in the absence of oxygen at room temperature in dimethylsulfoxide (DMSO) using $4.8 \mathrm{~W}$ red LED lamp as a light source $\left(\lambda_{\max }=635 \mathrm{~nm}\right) .{ }^{b}$ Monomer conversion was determined by using ${ }^{1} \mathrm{H}$ NMR spectroscopy. ${ }^{c}$ Theoretical molecular weight was calculated using the following equation: $M_{\mathrm{n}, \mathrm{th}}=[M]_{\mathrm{o}} /[\mathrm{RAFT}] \times \mathrm{MW}^{\mathrm{M}} \times \alpha+\mathrm{MW}^{\mathrm{RAFT}}$, where $[M]_{\mathrm{o}},[\mathrm{RAFT}]_{\mathrm{o}}, \mathrm{MW}^{\mathrm{M}}, \alpha$, and MW $\mathrm{MFFT}^{\mathrm{RA}}$ correspond to initial monomer concentration, initial RAFT concentration, molar mass of monomer, conversion determined by ${ }^{1} \mathrm{H}$ NMR, and molar mass of RAFT agent. ${ }^{d}$ Molecular weight and polydispersity were determined by GPC analysis (DMAc as eluent) based on polystyrene standards. ${ }^{e}[\mathrm{MMA}]_{0}:[\mathrm{MAA}]_{0}:[\mathrm{RAFT}]:[\mathrm{Chl} \mathrm{a}]=100: 100: 1: 8 \times 10^{-4} \cdot{ }^{f}$ The reaction was carried out in $N, N$-dimethylformamide (DMF) under red LED light irradiation. ${ }^{g}$ The reaction was carried out in acetonitrile (MeCN) under red LED light irradiation. ${ }^{h}$ Not determined. ${ }^{i}$ Molecular weight determined by ${ }^{1} \mathrm{H}$ NMR. ${ }^{j}$ Methylation was carried out with trimethylsilyldiazomethane prior to GPC analysis (DMAc eluent) based on polystyrene standards. 
both $\mathrm{Chl}$ a and RAFT agents were essential to activate polymerization.

Further supporting evidence to the proposed mechanism was obtained through fluorescence quenching studies. The fluorescence spectra of $\mathrm{Chl}$ a in DMSO in the presence of varying concentration of RAFT agents, 4-cyanopentanoic acid dithiobenzoate (CPADB) and BTPA, are shown in ESI, Fig. S3 and S4. $\dagger$ The fluorescence of $\mathrm{Chl}$ a in DMSO achieves a maximum at $673 \mathrm{~nm}$ when excited at $433 \mathrm{~nm}$. Upon addition of RAFT agents (both CPADB and BTPA), progressive quenching of $\mathrm{Chl}$ a fluorescence with increasing concentrations of RAFT agents was observed. The decrease of emission is correlated with the Stern-Volmer equation, $I_{0} / I=1+k_{\mathrm{q}} \tau_{0}[Q]$, where $I_{0}$ and $I$ are the emission intensity in the absence and presence of quencher, $k_{\mathrm{q}}$ is the quenching rate constant, $\tau_{0}$ is the excited lifetime, $[Q]$ is the quencher concentration. Plotting $I_{0} / I$ ratio versus the concentration of quencher gives a straight line (ESI, Fig. S4 $\dagger$ ). These results suggest that the excited $\mathrm{Chl}$ a engages in single-electron transfer with both BTPA and CPADB.

In contrast to ruthenium and iridium catalysts, Chl a presents two absorption bands in the visible spectrum, i.e., at 430 and $665 \mathrm{~nm}$ (ESI, Fig. S2B $\dagger$ ), which correspond to the blue (Soret band) and red (Q-band) regions of the visible spectrum, respectively. ${ }^{27}$ It has been demonstrated that both absorption bands induce a PET process during photosynthesis. In our early attempts, we tested the polymerization of MMA and MA under blue $\left(\lambda_{\max }=461 \mathrm{~nm}\right)$ and red LED light $\left(\lambda_{\max }=635 \mathrm{~nm}\right)$ in DMSO. The polymerization of MMA was initially tested using dithiobenzoate (CPADB), whereas that of MA was tested using trithiocarbonate (BTPA). In the presence of RAFT agent and several hours of irradiation with a molar ratio of [monomer]: [RAFT agent] : $[\mathrm{Chl} \mathrm{a}]=200: 1: 8 \times 10^{-4}$, we observed a viscous reaction mixture, which indicated the generation of polymers. The polymerizations proceeded smoothly to high monomer conversions $(50 \%$ and $76 \%$ for MMA (Table 1, \#4) and MA (Table 1, \#1) after $20 \mathrm{~h}$ and $5 \mathrm{~h}$ of red light irradiation, respectively). The samples were also analyzed by GPC, which revealed the synthesis of well-defined polymers with narrow molecular weight distributions $\left(M_{\mathrm{w}} / M_{\mathrm{n}}<1.15\right)$ and a good control over molecular weights.

In addition, the polymerization of (meth)acrylamides (Table 1 , \# 11-12), methacrylates (Table 1, \#13,15-16), acrylate (Table $1, \# 14)$ and statistical copolymerization of methacrylic acid with methyl methacrylate (Table 1 , \# 24) were also successfully carried out in the presence of red light and blue light (ESI, Table $\mathrm{S} 1, \uparrow \# 1,3-6$, and 8) with the synthesis of polymers with narrow molecular weight distributions $\left(M_{\mathrm{w}} / M_{\mathrm{n}}<1.25\right)$. In the polymerization of DMAEMA, it was found that prolonged irradiation of monomer under blue light in the absence of RAFT agent and catalyst could lead to self-initiation (ESI, Table S1, $\uparrow \# 7$ ). However, no such initiation was reported upon irradiation with red light (Table 1, \#17).

In order to further test the versatility of $\mathrm{Chl}$ a, we decided to polymerize MA and MMA with RAFT agents other than CPADB and BTPA. Polymerization of MA with 3-benzylsulfanyl-thiocarbonylthiosulfanyl propionic acid (BSTP) was successful (Table 1, \# 18) but a little higher polydispersity was observed as compared to that BTPA was used. For MMA, polymerization with 2-cyano-2-propylbenzodithioate (CPD) (Table 1, \# 20) and 4-cyano-4-[(dodecylsulfanylthiocarbonyl)sulfanyl] pentanoic acid (CDTPA) (Table 1, \# 21) yielded polymers with narrow molecular weight distributions $\left(M_{\mathrm{w}} / M_{\mathrm{n}}<1.20\right)$; however, polymerization with 2-phenyl-2-propyl benzodithioate (CDB) (Table 1 , \# 19) yielded a slightly broader molecular weight distribution $\left(M_{\mathrm{w}} / M_{\mathrm{n}}=1.27\right)$ due to possibly slow initiation of RAFT agent leading to asynchronous chain propagation. Unfortunately, other thiocarbonylthio compounds, such as xanthate (methyl 2[(ethoxycarbonothioyl) sulfanyl]propanoate) and dithiocarbamate (cyanomethyl methyl-(phenyl)carbamodithioate) investigated for the polymerization of vinyl acetate were unsuccessful (data not shown).

We then tested the tolerance of $\mathrm{Chl}$ a with different solvents, including DMF, acetonitrile (MeCN), and toluene. $\mathrm{Chl}$ a was effective in polymerizing MA in both DMF (Table 1, \# 22) and MeCN (Table 1, \# 23) with low polydispersities $\left(M_{\mathrm{w}} / M_{\mathrm{n}}<1.10\right)$, however, the polymerization in $\mathrm{MeCN}$ was much slower. In toluene, no polymerization was observed. In comparing to all the investigated solvents, the strongest ligands for $\mathrm{Chl}$ a is DMF and DMSO with donicities of 26.6 and $29.8 \mathrm{kcal} \mathrm{mol}^{-1}$ respectively, ${ }^{37,38}$ which yields high monomer conversion and good polymerization control. On the other hand, MeCN and toluene have donicities of 19.0 and $0.1 \mathrm{kcal} \mathrm{mol}^{-1}, 37,38$ thereby making them poor ligands to solubilize $\mathrm{Chl} \mathrm{a}$, which result in a poor control of polymerization.

We subsequently investigated the polymerization kinetics using online Fourier transform near-infrared (FTNIR) spectroscopy, which measured the monomer conversions by following the decrease in the vinylic $\mathrm{C}-\mathrm{H}$ stretching overtone of monomers at $\sim 6200 \mathrm{~cm}^{-1}$, as described in previous publications. ${ }^{20} \ln \left([M]_{0} /[M]_{t}\right)$ was plotted against exposure time, as shown in Fig. 1A, to determine the apparent propagation rate constant $\left(k_{\mathrm{p}}^{\text {app }}\right)$. Interestingly, a higher propagation rate constant $\left(k_{\mathrm{p}}^{\mathrm{app}}(\mathrm{red})=5.6 \times 10^{-3} \mathrm{~min}^{-1}\right)$ and a shorter induction period $(50 \mathrm{~min})$ were observed under red light compared to those observed under blue light $\left(k_{\mathrm{p}}^{\mathrm{app}}(\mathrm{blue})=2.4 \times 10^{-3} \mathrm{~min}^{-1}\right.$ and $100 \mathrm{~min}$ induction period). These findings are contrary to the observed specific absorption coefficient $(\alpha)$ for $\mathrm{Chl}$ a. Based on previous studies, specific absorption coefficient of $\mathrm{Chl}$ a was determined to be 96.6-100.9 at $665 \mathrm{~nm}$ (red light) and 125.1131.5 at $430 \mathrm{~nm}$ (blue light). ${ }^{28}$ In other words, polymerization should be faster in blue light than red light. However, these conflicting results can be attributed to the efficiency of $\mathrm{Chl}$ a in red light as compared to blue light. Although $\mathrm{Chl}$ a is able to absorb high energy blue light, the lowest energy transition only occurs at around $660 \mathrm{~nm}$ in solution. This low wavelength transition leads to a change in electron distribution within the porphyrin nuclear framework and eventually electron transfer to a strong electron acceptor. ${ }^{39}$ In the presence of blue light, $\mathrm{Chl}$ a is excited to a higher vibrational and electronic singlet states, but this energy is quickly radiated to the environment as random translational energy of heat to reach the first excited singlet state where one of the modes of energy transfer is through oxidation of $\mathrm{Chl} \mathrm{a.}{ }^{28}$ We propose that the higher activity of Chl a in polymerization of MA lies in its efficiency in 

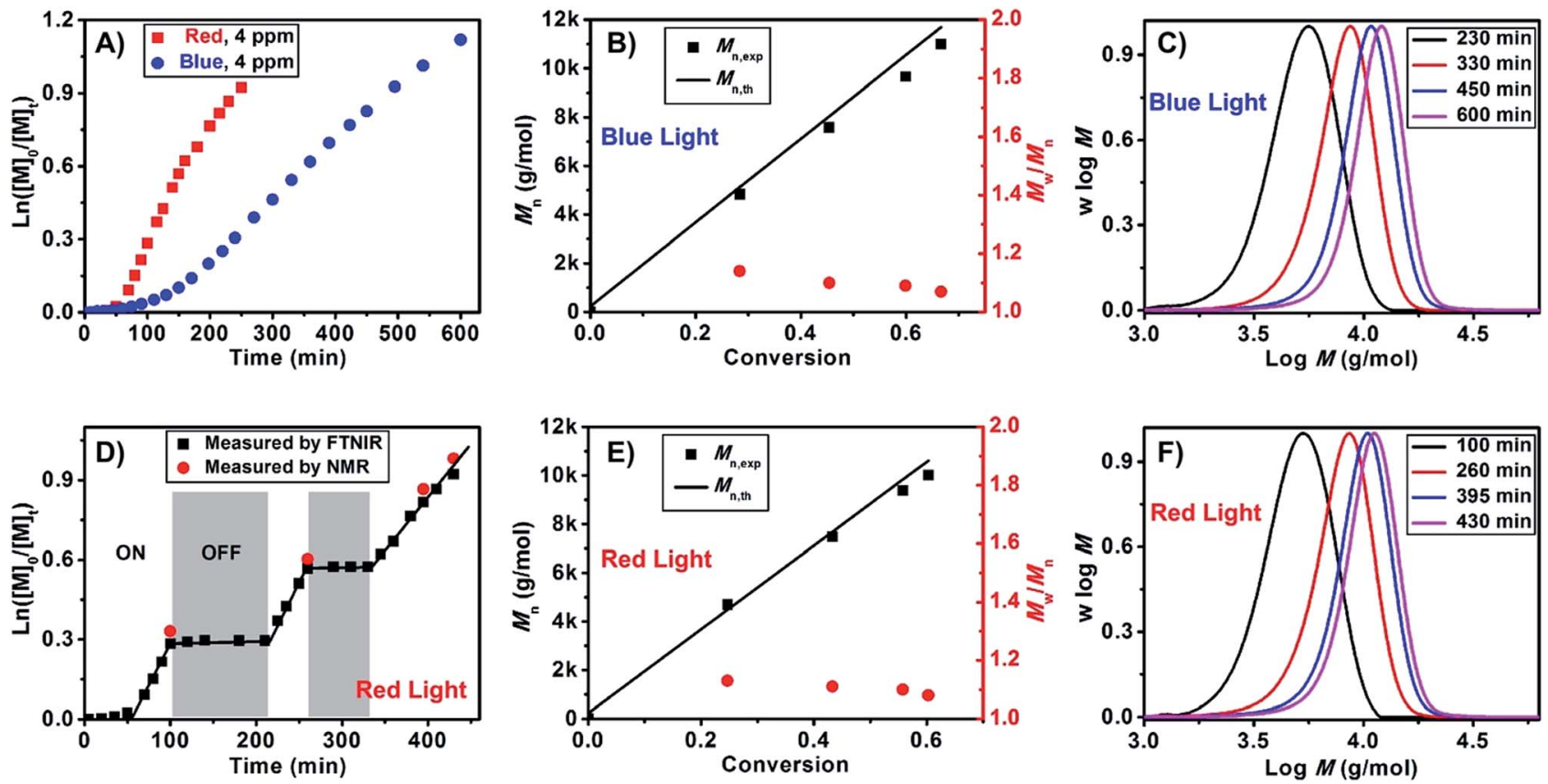

Fig. 1 Online Fourier transform near-infrared (FTNIR) measurement for kinetic study of PET-RAFT polymerization of methyl acrylate (MA) at room temperature with $\mathrm{Chl}$ a as the photoredox biocatalyst and BTPA as the chain transfer agent under blue $(\mathrm{A}, \mathrm{B}$ and $\mathrm{C})$ and red $(\mathrm{A}, \mathrm{D}, \mathrm{E}$ and $\mathrm{F})$ light irradiation, using molar ratio of $[\mathrm{MA}]$ : [BTPA] : $\left[\mathrm{Chl}\right.$ a] $=200: 1: 8 \times 10^{-4}$ in DMSO. (A) Plot of $\ln \left([\mathrm{M}]_{0} /[\mathrm{M}]_{t}\right)$ vs. exposure time under blue (blue squares) and red (red dots) lights; $(B$ and $E) M_{n} v s$. conversion for blue (B) and red (E) light system; ( $C$ and $F$ ) molecular weight distributions at different time points under blue (C) and red (F) light irradiation; (D) plot of $\ln \left([M]_{0} /[M]_{t}\right)$ vs. time for conversion of MA in the presence ("ON") and absence ("OFF") of red light.

absorbing low energy red light which leads to photoinduced electron transfer to BTPA. Moreover, the higher propagation rate for red light as compared to blue light may also come from competitive absorption between RAFT agent and Chl a. RAFT agents such as CPADB and BTPA have a strong absorption peak at $305 \mathrm{~nm}$ (and a weak absorption at $520 \mathrm{~nm}$ ) and exist in excess as compared to $\mathrm{Chl} \mathrm{a}$. Upon addition of $\mathrm{Chl}$ a, the Soret band at $430 \mathrm{~nm}$ of $\mathrm{Chl}$ a overlaps with the shoulder of the strong absorption peak of RAFT agents (ESI, Fig. S11A and S11B $\dagger$ ). This overlap leads to competitive absorption between $\mathrm{Chl}$ a and BTPA/CPADB which may result in lower efficiency of $\mathrm{Chl}$ a in blue light as compared to red light. In addition, no other intense light absorption is observed in the visible light spectrum for $\mathrm{Chl}$ a. Therefore, polymerization should be observed only in blue and red lights. To test this hypothesis, a polymerization of MA was carried out under green LED light $\left(\lambda_{\max }=530\right.$ $\mathrm{nm}, 4.8 \mathrm{~W}$ ). As expected, no polymerization was observed under green light, which is attributed to the absence of strong absorbance band. After purification, the presence of thiocarbonylthio end groups in both PMA and PMMA was confirmed by NMR (ESI, Fig. S5 and S6†) and UV-vis spectroscopy (ESI, Fig. S7†). End group fidelity was quantified to be greater than $95 \%$ for both polymerizations under blue and red LED light.

Because there are fewer reports ${ }^{40-42}$ employing low-energy light ( $>600 \mathrm{~nm}$, or red light) to activate polymerization than those using high-energy light ( $<400 \mathrm{~nm}$, blue or UV light), ${ }^{14,43-56}$ we explored the polymerization of MMA, MA and other monomers under red light in various solvents. Several aliquots were taken at specific intervals during the polymerization of MMA under red light to measure the molecular weights and molecular weight distributions by GPC. By plotting $M_{\mathrm{n}}$ and polydispersity values against monomer conversion, we observed the characteristics of living radical polymerization, particularly a linear increase in $M_{\mathrm{n}}$ and a slight decrease in polydispersity (Fig. 1E and F and ESI, Fig. S8B and S8C $\dagger$ ) for both MA and MMA. A lower polydispersity was obtained under red light, suggesting better control under red light. An additional feature introduced in this experiment was switching "ON" and "OFF" the light source to demonstrate that $\mathrm{Chl}$ a was acting as a molecular switch, which afforded temporal and potentially spatial control. The polymerization of both MA (Fig. 1D) and MMA (ESI, Fig. S8A $\dagger$ ) was observed when the light was "ON". In the absence of light ("OFF"), no monomer conversion was recorded. Aliquots of the reaction mixtures used for MA and MMA polymerization were also taken at specific intervals to measure the molecular weights and molecular weight distributions by GPC and the monomer conversions by NMR analysis. As indicated in Fig. 1D, the conversions at specific times, calculated by FTNIR, were in close agreement with the NMR data.

Subsequently, we investigated the effect of $\mathrm{Chl}$ a concentration on the polymerization kinetics of MMA via on-line FTNIR. The polymerizations were carried out in the presence of $4 \mathrm{ppm}$ and $10 \mathrm{ppm}$ of $\mathrm{Chl}$ a relative to the monomer concentration; samples were taken from the reaction mixture at designated times for GPC analysis. By plotting $\ln \left([M]_{0} /[M]_{t}\right)$ against time (Fig. 2), we observed linear kinetics that fit the criteria within a first-order approximation for both polymerizations. The 


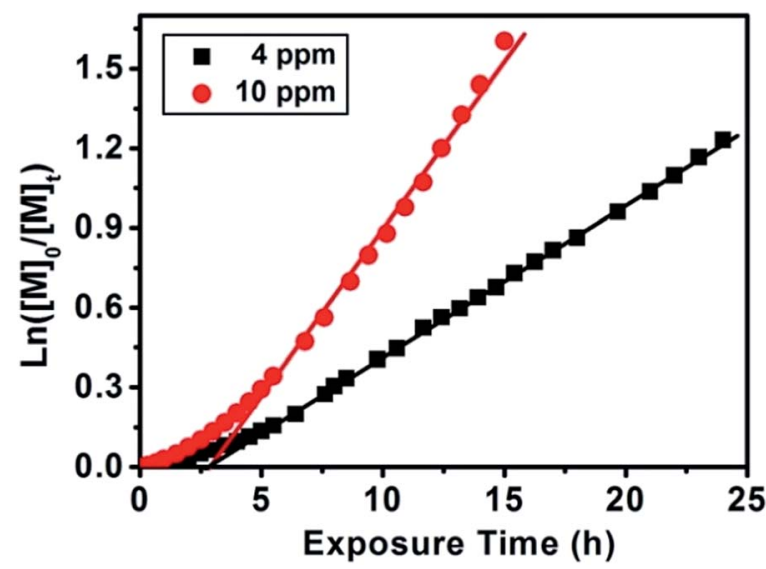

Fig. 2 Plotting $\ln \left([M]_{0} /[M]_{t}\right)$ against exposure time measured by online FTNIR for different Chl a concentrations (4 ppm against 10 ppm relative to monomer concentration) for the polymerization of MMA at room temperature under red light irradiation with CPADB as chain transfer agent using molar ratio of [MMA] : [CPADB] $=200: 1$ in DMSO. GPC results $\left(M_{n}\right.$ vs. conversion and molecular weight distributions) showed in Fig. $\mathrm{S} 8 \uparrow$ for 4 ppm and Fig. $59 \dagger$ for 10 ppm.

propagation rate constants at $10 \mathrm{ppm}$ were determined to be $k_{\mathrm{p}}^{\text {app }}($ red $)=0.133 \mathrm{~h}^{-1}$ and $k_{\mathrm{p}}^{\text {app }}($ red $)=0.057 \mathrm{~h}^{-1}$ at $4 \mathrm{ppm}$. Consequently, the presence of a higher concentration of catalyst resulted in an increase in the overall rate of polymerization. In addition, the induction period observed in the polymerization of MMA (Fig. 2) and MA (Fig. 1A) can be attributed to stable and long lifetime intermediate of radical addition product in the RAFT process, which was observed in conventional RAFT polymerization and proved by other research groups. ${ }^{57-64}$ Analysis of aliquots obtained throughout the course of the polymerization showed a linear increase in molecular weight as a function of conversion. However, a decrease in polydispersity was only observed for the $4 \mathrm{ppm}$ catalyst concentration and not for the 10 ppm concentration (ESI, Fig. S8B \& C and S9B \& C, $\dagger$ respectively). The higher molecular weight distribution in $10 \mathrm{ppm}$ as compared to $4 \mathrm{ppm}$ is due to termination from oxygen contamination introduced by frequent sampling during the reaction. A repetition of these experiments with no sampling during the course of reaction revealed that at conversions $94 \%$ for both 10 ppm (Table 1, \# 6) and 4 ppm (Table 1, \# 5) Chl a concentrations (relative to monomer concentration), the molecular weight distributions of the homopolymers remain low (PDI < 1.20). Surprisingly, an increase in catalyst concentration from $4 \mathrm{ppm}$ to $10 \mathrm{ppm}$ led to a higher propagation rate constant with negligible changes to the molecular weight and molecular weight distributions (in an inert environment) even at high monomer conversions (>90\%) (ESI, Fig. S10†). As both 4 ppm and $10 \mathrm{ppm}$ Chl a show a similar trend at high monomer conversions, we attempted to further increase the concentration of Chl a to 25 ppm (Table 1, \# 7-9) to determine the validity of this trend. Interestingly, Chl a concentrations of 4 ppm (Fig. 2) and 25 ppm (Table $1, \# 7$ ) have similar polymerization rates by comparing the polymerization of MMA at roughly $70 \%$ monomer conversion while the polymerization at $10 \mathrm{ppm}$ (Table 1 , \#
6) is much faster than that at $25 \mathrm{ppm}$. The lower polymerization rate for $25 \mathrm{ppm}$ compared to $10 \mathrm{ppm}$ of $\mathrm{Chl}$ a is related to selfquenching of Chl solutions at higher concentrations. The mechanism of concentration quenching relies on transfer of excitation energy to statistical pairs of $\mathrm{Chl}$ a, which are separated by small distance in solutions, acting as quenching sites. At low concentration of $\mathrm{Chl}$ a solutions, fluorescence intensity is independent of concentration; however, at higher concentrations, fluorescence intensity decreases as there is rapid transport of excitonic energy to quenching sites. In the presence of these quenching sites, reduction of RAFT agent through photoinduced electron transfer competes with energy transfer to statistical pairs of Chl a molecules leading to observation of a slower rate for $25 \mathrm{ppm}$ of $\mathrm{Chl}$ a as compared to 4 ppm of Chl a. ${ }^{65-71}$

The livingness of the polymers synthesized by PET-RAFT using Chl a was further investigated by chain extensions of PMA and PMMA under both blue and red light. PMA macroinitiators were first synthesized in DMSO under irradiation by blue and red light $\left(M_{\mathrm{n}, \mathrm{GPC}}=8810 \mathrm{~g} \mathrm{~mol}^{-1}, M_{\mathrm{w}} / M_{\mathrm{n}}=1.10\right.$ and $46 \%$ monomer conversion for both lights) with BTPA in the presence of $4 \mathrm{ppm} \mathrm{Chl} \mathrm{a} \mathrm{for} 3$ and $2 \mathrm{~h}$, respectively. A molar ratio of $500: 1$ of the monomer $N, N$-dimethylacrylamide (DMA) to the PMA macroinitiator was then used for chain extension in the presence of $4 \mathrm{ppm}$ of Chl a. Successful chain extension was observed for both macroinitiators under blue and red light (Fig. 3A and C), with the molecular weight distributions showing a complete shift in both macroinitiators to higher molecular weights over time. In addition, the UV and RI curves for the diblock copolymers under red and blue lights at $5 \mathrm{~h}$ (Fig. 3B and D), show a perfect overlap with the absence of dead chains and a decrease in polydispersities (PMA- $b$-PDMA : $M_{\mathrm{n}, \mathrm{GPC}, \mathrm{red}}=45570 \mathrm{~g} \mathrm{~mol}^{-1}$, $M_{\mathrm{w}} / M_{\mathrm{n}}=1.08$ and $79 \%$ monomer conversion for red light, and $M_{\text {n,GPC,blue }}=41380 \mathrm{~g} \mathrm{~mol}^{-1}, M_{\mathrm{w}} / M_{\mathrm{n}}=1.08$ and $69 \%$ monomer conversion for blue light). Successful chain extension of the PMMA macroinitiators with tert-butyl methacrylate ( $t$ BuMA) (ESI, Fig. S12†) and oligo(ethylene glycol) methyl ether methacrylate (OEGMA) (ESI, Fig. S13†) monomers with a molar ratio of [monomer]: [macroinitiator] = 500:1 was also demonstrated by GPC.

In order to investigate the stability of chlorophyll molecule in PET-RAFT polymerization upon prolonged exposure to light, catalyst photostability test was carried out with online FTNIR measurement similar as that we reported on ruthenium before. $^{72}$ For this investigation, two DMSO solutions in two quartz cuvettes containing the same concentration of Chl a (4 ppm) were both degassed with nitrogen. The first cuvette was pre-irradiated under red light for 16 hours, while the second was kept in the dark as a parallel control. Both of them were then employed for the polymerization of MA in the presence of BTPA with a molar ratio of [MA] : [BTPA] : [Chl a] $=200: 1: 8 \times$ $10^{-4}$. The online FTNIR study showed that the polymerization of MA (Fig. 4) in control system $\left(k_{\mathrm{p}}^{\text {app }}(\right.$ control $)=5.23 \times 10^{-3}$ $\min ^{-1}$ ) was faster than that in pre-irradiated one $\left(k_{\mathrm{p}}^{\text {app }}\right.$ (preirradiated) $=3.54 \times 10^{-3} \mathrm{~min}^{-1}$ ), indicating of partial degradation of Chl a during light irradiation. This is possibly 
(A)
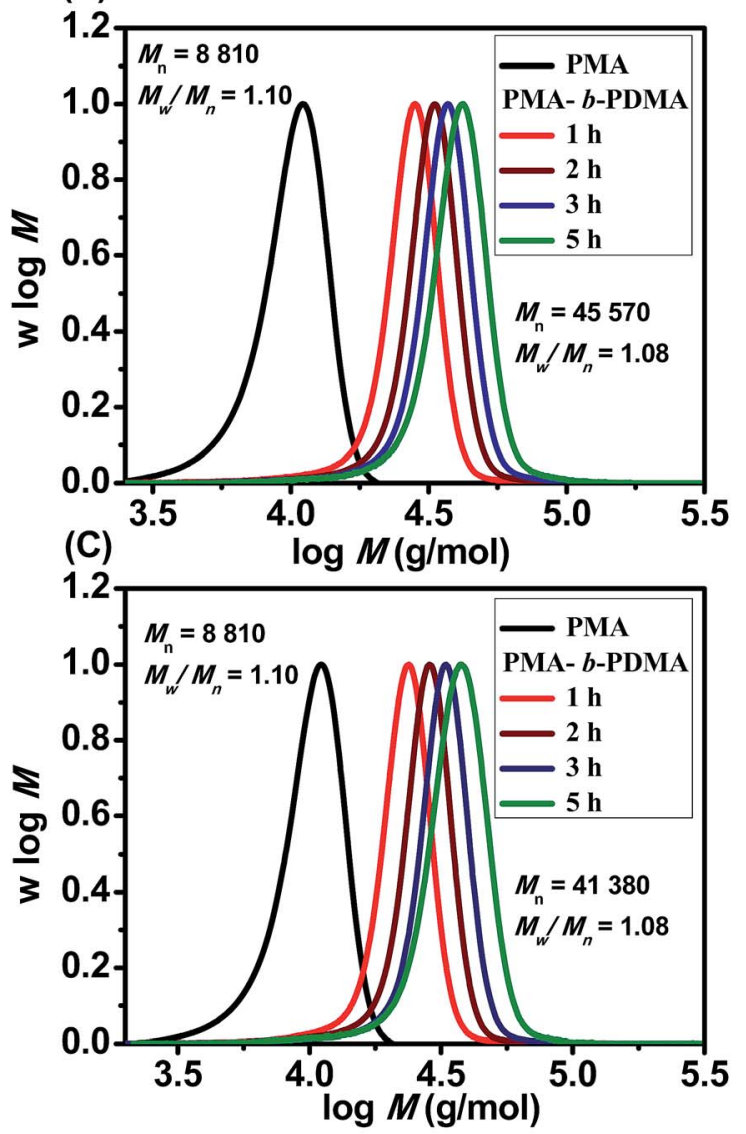

(B)
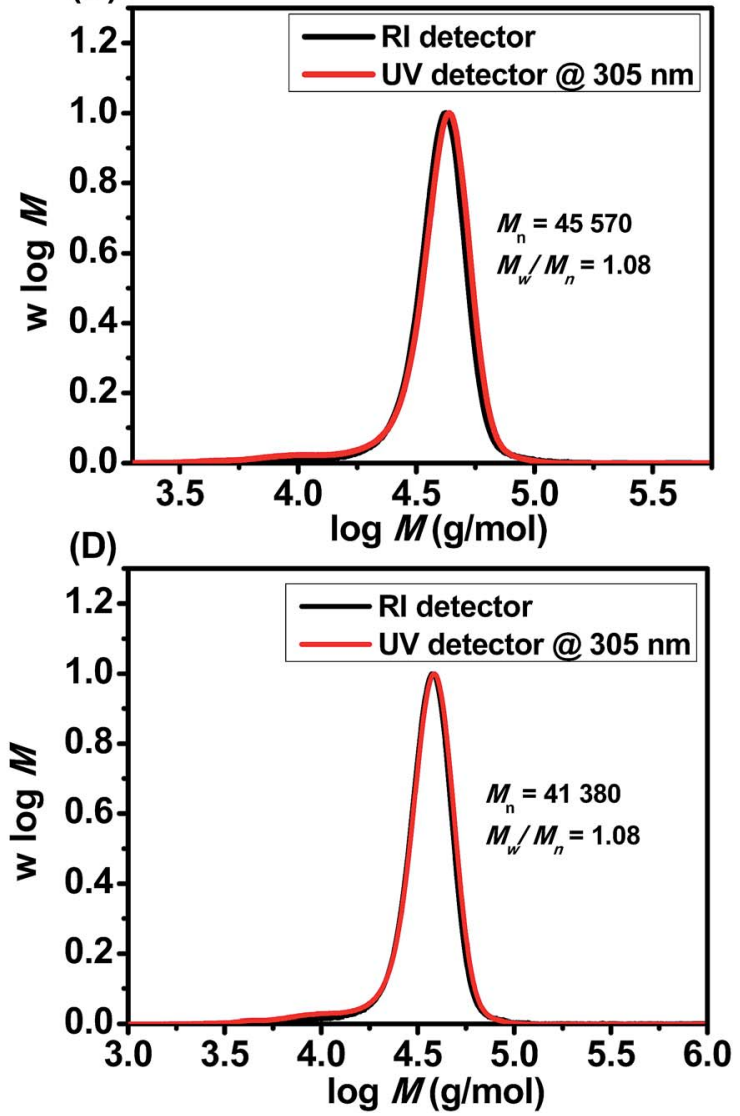

Fig. 3 Molecular weight distributions of PMA macroinitiators and their diblock copolymers prepared at room temperature in the presence of Chl $a$ and BTPA as chain transfer in DMSO: (A) molecular weight distributions of PMA macroinitiator and PMA- $b$-PDMA diblock copolymers at 1, 2, 3, and $5 \mathrm{~h}$ prepared under red light irradiation; (B) overlap of UV and RI GPC traces of PMA- $b$-PDMA diblock copolymer obtained at $5 \mathrm{~h}$ from (A); (C) molecular weight distributions of PMA macroinitiator and PMA-b-PDMA diblock copolymers at 1, 2, 3 and $5 \mathrm{~h}$ prepared under blue light irradiation; and (D) overlap of UV and RI GPC traces of PMA-b-PDMA diblock copolymer obtained at $5 \mathrm{~h}$ from (C).

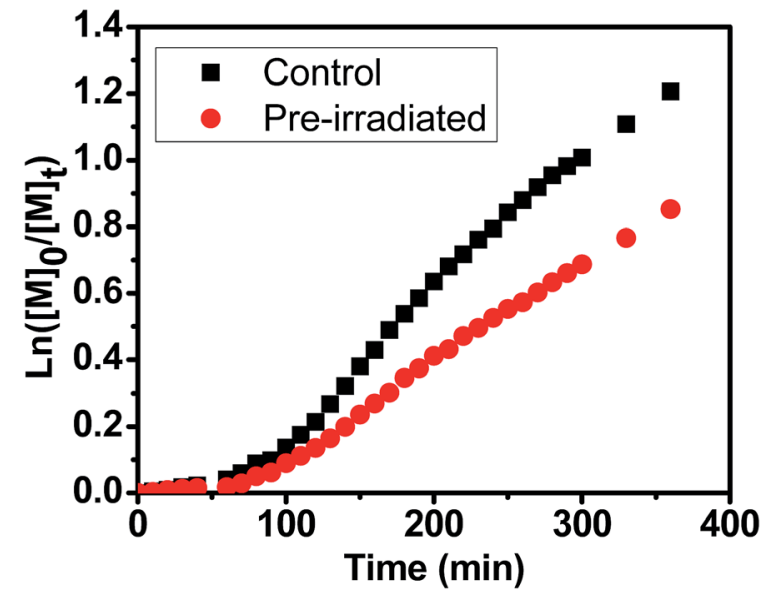

Fig. 4 Kinetic study with online Fourier transform near-infrared (FTNIR) measurement for the polymerization of methyl acrylate (MA) in the presence and absence of irradiation under red light with $\mathrm{Chl}$ a as the photoredox biocatalyst and BTPA as the chain transfer using molar ratio of $[\mathrm{MA}]$ : [BTPA] : [Chl a] $=200: 1: 8 \times 10^{-4}$ in DMSO. attributed to the formation of a tetrapyrrole structure through the cleavage of the porphyrin ring at one of the methine bridges. ${ }^{73}$

\section{Conclusion}

In this study, we demonstrated, for the first time, the use of Chl a to mediate a living radical polymerization under blue and red LED light via photoinduced electron transfer - reversible addition fragmentation chain transfer (PET-RAFT) polymerization. This polymerization requires only ppm levels of $\mathrm{Chl}$ a to activate the PET-RAFT process. Because iridium- and ruthenium-based catalysts are expensive and potentially toxic, this study represented a significant step towards the development of new sustainable and non-transition metal catalysts from bioresources. A wide range of monomer families, including (meth) acrylamide and (meth)acrylates containing a large variety of functional groups, such as carboxylic acid, amine, alcohol, and glycidyl groups, was successfully polymerized within a few hours and showed excellent control over molecular weight and polydispersity. 


\section{Acknowledgements}

CB thanks the University of New South Wales for funding and Australian Research Council (ARC-FT 12100096).

\section{Notes and references}

1 P. W. Atkins and P. W. Atkins, Elements of physical chemistry, Oxford University Press, Oxford, 6th edn, 2013.

2 G. Ciamician, Science, 1912, 36, 385-394.

3 J. A. Bassham, A. A. Benson and M. Calvin, J. Biol. Chem., 1950, 185, 781-787.

4 D. A. Nicewicz and D. W. C. MacMillan, Science, 2008, 322, 77-80.

5 J. M. R. Narayanam and C. R. J. Stephenson, Chem. Soc. Rev., 2011, 40, 102-113.

6 J. W. Tucker and C. R. J. Stephenson, J. Org. Chem., 2012, 77, 1617-1622.

7 T. P. Yoon, M. A. Ischay and J. Du, Nat. Chem., 2010, 2, 527532.

8 C. K. Prier, D. A. Rankic and D. W. C. MacMillan, Chem. Rev., 2013, 113, 5322-5363.

9 D. Roy and B. S. Sumerlin, Macromol. Rapid Commun., 2014, 35, 174-179.

10 N. V. Alfredo, N. E. Jalapa, S. L. Morales, A. D. Ryabov, R. Le Lagadec and L. Alexandrova, Macromolecules, 2012, 45, 8135-8146.

11 K. Kalyanasundaram, Coord. Chem. Rev., 1982, 46, 159-244.

12 J. Lalevée, N. Blanchard, M.-A. Tehfe, M. Peter, F. MorletSavary and J. Fouassier, Polym. Bull., 2012, 68, 341-347.

13 D.-L. Versace, J. Cerezo Bastida, C. Lorenzini, C. CachetVivier, E. Renard, V. Langlois, J.-P. Malval, J.-P. Fouassier and J. Lalevée, Macromolecules, 2013, 46, 8808-8815.

14 B. P. Fors and C. J. Hawker, Angew. Chem., Int. Ed., 2012, 51, 8850-8853.

15 B. P. Fors, J. E. Poelma, M. S. Menyo, M. J. Robb, D. M. Spokoyny, J. W. Kramer, J. H. Waite and C. J. Hawker, J. Am. Chem. Soc., 2013, 135, 14106-14109.

16 F. A. Leibfarth, K. M. Mattson, B. P. Fors, H. A. Collins and C. J. Hawker, Angew. Chem., Int. Ed., 2013, 52, 199-210.

17 J. E. Poelma, B. P. Fors, G. F. Meyers, J. W. Kramer and C. J. Hawker, Angew. Chem., Int. Ed., 2013, 52, 6844-6848.

18 N. J. Treat, H. Sprafke, J. W. Kramer, P. G. Clark, B. E. Barton, J. Read de Alaniz, B. P. Fors and C. J. Hawker, J. Am. Chem. Soc., 2014, 136, 16096-16101.

19 N. J. Treat, B. P. Fors, J. W. Kramer, M. Christianson, C.-Y. Chiu, J. R. d. Alaniz and C. J. Hawker, ACS Macro Lett., 2014, 3, 580-584.

20 S. Shanmugam, J. Xu and C. Boyer, Macromolecules, 2014, 47, 4930-4942.

$21 \mathrm{~J} . \mathrm{Xu}, \mathrm{K}$. Jung, A. Atme, S. Shanmugam and C. Boyer, J. Am. Chem. Soc., 2014, 136, 5508-5519.

22 K. Schroder, K. Matyjaszewski, K. J. T. Noonan and R. T. Mathers, Green Chem., 2014, 16, 1673-1686; A. Simakova, M. Mackenzie, S. Averick, S. Park and K. Matyjaszewski, Angew. Chem. Int. Ed., 2013, 52, 1214812151.
23 C. S. Allardyce and P. J. Dyson, Platinum Met. Rev., 2001, 45, 62-69.

24 M. E. El-Khouly, Y. Araki, M. Fujitsuka, A. Watanabe and O. Ito, Photochem. Photobiol., 2001, 74, 22-30.

25 A. Johnston, J. Scaggs, C. Mallory, A. Haskett, D. Warner, E. Brown, K. Hammond, M. M. McCormick and O. M. McDougal, J. Chem. Educ., 2013, 90, 796-798.

26 H. T. Quach, R. L. Steeper and G. W. Griffin, J. Chem. Educ., 2004, 81, 385.

27 A. R. Wellburn, J. Plant Physiol., 1994, 144, 307-313.

28 L. P. Vernon and G. R. Seely, The chlorophylls, Academic Press, New York, 1966.

29 K. M. Smith, D. A. Goff and R. J. Abraham, Org. Magn. Reson., 1984, 22, 779-783.

30 R. J. Abraham and A. E. Rowan, in Chlorophylls, ed. H. Scheer, CRC Press, Boca Raton, FL, 1991,.pp. 797-834.

31 C. Fu, J. Xu, L. Tao and C. Boyer, ACS Macro Lett., 2014, 3, 633-638.

32 G. L. Zubay and L. Z. Geoffrey, Biochemistry, W. M. C. Brown Publishers, Dubuque, Iowa, 3rd edn, 1993.

33 R. G. Mortimer, in Physical Chemistry, Academic Press, Burlington, 2nd edn, 2000, pp. 751-815.

34 D. C. Borg, J. Fajer, R. H. Felton and D. Dolphin, Proc. Natl. Acad. Sci. U. S. A., 1970, 67, 813-820.

35 D. Dolphin and R. H. Felton, Acc. Chem. Res., 1974, 7, 26-32. 36 J. H. Fuhrhop and D. Mauzerall, J. Am. Chem. Soc., 1969, 91, 4174-4181.

37 A. Agostiano, P. Cosma, M. Trotta, L. Monsù-Scolaro and N. Micali, J. Phys. Chem. B, 2002, 106, 12820-12829.

38 V. Gutmann, Coord. Chem. Rev., 1976, 18, 225-255.

39 A. J. Govindjee and R. Govindjee, Bioenergetics of photosynthesis, Academic Press, New York, 1974.

40 M. Tehfe, F. Louradour, J. Lalevée and J.-P. Fouassier, Appl. Sci., 2013, 3, 490-514.

41 P. Xiao, F. Dumur, B. Graff, J. P. Fouassier, D. Gigmes and J. Lalevée, Macromolecules, 2013, 46, 6744-6750.

42 P. Xiao, F. Dumur, J. Zhang, J. P. Fouassier, D. Gigmes and J. Lalevée, Macromolecules, 2014, 47, 3837-3844.

43 M. A. Tasdelen, M. Ciftci and Y. Yagci, Macromol. Chem. Phys., 2012, 213, 1391-1396.

44 M. Ciftci, M. A. Tasdelen and Y. Yagci, Polym. Chem., 2014, 5, 600-606.

45 T. G. Ribelli, D. Konkolewicz, S. Bernhard and K. Matyjaszewski, J. Am. Chem. Soc., 2014, 136, 13303-13312. 46 Y. Zhao, M. Yu, S. Zhang, Y. Liu and X. Fu, Macromolecules, 2014, 47, 6238-6245.

47 T. G. Ribelli, D. Konkolewicz, X. Pan and K. Matyjaszewski, Macromolecules, 2014, 47, 6316-6321.

48 A. Anastasaki, V. Nikolaou, A. Simula, J. Godfrey, M. Li, G. Nurumbetov, P. Wilson and D. M. Haddleton, Macromolecules, 2014, 47, 3852-3859.

49 A. Anastasaki, V. Nikolaou, G. S. Pappas, Q. Zhang, C. Wan, P. Wilson, T. P. Davis, M. R. Whittaker and D. M. Haddleton, Chem. Sci., 2014, 5, 3536-3542.

50 A. Anastasaki, V. Nikolaou, Q. Zhang, J. Burns, S. R. Samanta, C. Waldron, A. J. Haddleton, R. McHale, 
D. Fox, V. Percec, P. Wilson and D. M. Haddleton, J. Am. Chem. Soc., 2014, 136, 1141-1149.

51 J. Xu, A. Atme, A. F. Marques Martins, K. Jung and C. Boyer, Polym. Chem., 2014, 5, 3321-3325.

52 A. Wolpers and P. Vana, Macromolecules, 2014, 47, 954-963. 53 J. Lalevée, M. Peter, F. Dumur, D. Gigmes, N. Blanchard, M.-A. Tehfe, F. Morlet-Savary and J. P. Fouassier, Chem.Eur. J., 2011, 17, 15027-15031.

54 (a) J. Lalevée, M.-A. Tehfe, F. Dumur, D. Gigmes, N. Blanchard, F. Morlet-Savary and J. P. Fouassier, ACS Macro Lett., 2012, 1, 286-290; (b) J. Lalevee, D. Gigmes, F. Dumur, Y. Guillaneuf, S. teliel, S. Telitel, O. Soppera, m. lepeltier, J.-P. Fouassier, J. Poly, P. Fioux and F. MorletSavary, Polym. Chem., 2014, DOI: 10.1039/c4py01358a; (c) G. M. Miyake and J. C. Theriot, Macromolecules, 2014, DOI: 10.1021/ma502044f.

55 J. Lalevée, S. Telitel, P. Xiao, M. Lepeltier, F. Dumur, F. Morlet-Savary, D. Gigmes and J.-P. Fouassier, Beilstein J. Org. Chem., 2014, 10, 863-876.

56 D. Konkolewicz, K. Schröder, J. Buback, S. Bernhard and K. Matyjaszewski, ACS Macro Lett., 2012, 1, 1219-1223.

57 L. Wong, C. Boyer, Z. Jia, H. M. Zareie, T. P. Davis and V. Bulmus, Biomacromolecules, 2008, 9, 1934-1944.

58 X. Han, J. Fan, J. He, J. Xu, D. Fan and Y. Yang, Macromolecules, 2007, 40, 5618-5624.

59 M. Benaglia, E. Rizzardo, A. Alberti and M. Guerra, Macromolecules, 2005, 38, 3129-3140.

60 S. Perrier, C. Barner-Kowollik, J. F. Quinn, P. Vana and T. P. Davis, Macromolecules, 2002, 35, 8300-8306.
61 C. Barner-Kowollik, M. Buback, B. Charleux, M. L. Coote, M. Drache, T. Fukuda, A. Goto, B. Klumperman, A. B. Lowe, J. B. McLeary, G. Moad, M. J. Monteiro, R. D. Sanderson, M. P. Tonge and P. Vana, J. Polym. Sci., Part A: Polym. Chem., 2006, 44, 5809-5831.

62 B. Klumperman, E. T. A. van den Dungen, J. P. A. Heuts and M. J. Monteiro, Macromol. Rapid Commun., 2010, 31, 18461862.

63 D. Konkolewicz, B. S. Hawkett, A. Gray-Weale and S. Perrier, Macromolecules, 2008, 41, 6400-6412.

64 K. Ranieri, G. Delaittre, C. Barner-Kowollik and T. Junkers, Macromol. Rapid Commun., 2014, DOI: 10.1002/ marc.201400518.

65 W.-J. Shi, J. Barber and Y. Zhao, J. Phys. Chem. B, 2013, 117, 3976-3982.

66 W. F. Watson and R. Livingston, J. Chem. Phys., 1950, 18, 802-809.

67 A. G. Tweet, W. D. Bellamy and G. L. Gaines, J. Chem. Phys., 1964, 41, 2068-2077.

68 G. S. Beddard, S. E. Carlin and G. Porter, Chem. Phys. Lett., 1976, 43, 27-32.

69 M. L. Agrawal, J. P. Chauvet and L. K. Patterson, J. Phys. Chem., 1985, 89, 2979-2982.

70 G. S. Beddard and G. Porter, Nature, 1976, 260, 366-367.

71 R. S. Knox, J. Phys. Chem., 1994, 98, 7270-7273.

72 J. Xu, K. Jung and C. Boyer, Macromolecules, 2014, 47, 42174229.

73 C. E. Jones and R. A. Mackay, J. Phys. Chem., 1978, 82, 63-65. 